\title{
INFLUENZA VACCINATION PREVALENCE AMONG THE ELDERLY AND INDIVIDUALS WITH CHRONIC DISEASE, AND FACTORS AFFECTING VACCINATION UPTAKE
}

\author{
Pınar Korkmaz', Türkan Paşalı Kilit², Kevser Onbaşı², Duru Mıstanoglu Ozatag ${ }^{1}$, Onur Toka ${ }^{3}$ \\ ${ }^{1}$ Department of Infectious Diseases and Clinical Microbiology, Faculty of Medicine, Dumlupinar University, Kütahya, Turkey \\ ${ }^{2}$ Department of Internal Medicine, Faculty of Medicine, Dumlupinar University, Kütahya, Turkey \\ ${ }^{3}$ Department of Statistics, Hacettepe University, Ankara, Turkey
}

\begin{abstract}
SUMMARY
Objective: Our aim is to evaluate influenza vaccination rates among the elderly and individuals with underlying chronic disease, and factors that affect vaccination uptake.

Methods: The study comprised individuals aged 18-65 years with underlying chronic diseases, and individuals aged over 65 years. Literaturebased questionnaires prepared by the researcher regarding vaccination were completed through face-to-face interviews by the principal investigator. Results: A total of 818 participants were included in the study, $257(31.4 \%)$ were males. The mean age of participants was $57.47 \pm 14.11$ years; $274(33.5 \%)$ were aged 65 years and over. One hundred and three (12.6\%) participants stated that they received vaccinations against influenza annually, and $144(17.6 \%)$ stated that they had vaccination against influenza in the 2015/16 or 2016/17 season. Fifty-two (19\%) participants aged more than 65 years stated that they received vaccinations against influenza annually, $75(27.4 \%)$ stated that they had vaccination against influenza in the 2015/16 or 2016/17 season. The most commonly determined reasons for not receiving vaccination were not knowing that it was necessary $(34 \%)$ and believing that vaccination was not necessary because they were healthy $(26 \%)$. Statistically significantly more participants who gained their knowledge from a physician were vaccinated than those whose knowledge came from other sources $(p<0.05)$. Participants who considered that they had sufficient information about influenza were vaccinated more frequently, the results were statistically significant $(p<0.05)$.

Conclusion: Informing target risk groups about influenza vaccination by physicians and increasing awareness about influenza may contribute to increasing vaccination rates.
\end{abstract}

Key words: influenza, vaccination, elderly people, chronic disease, risk group

Address for correspondence: P. Korkmaz, Department of Infectious Diseases and Clinical Microbiology, Faculty of Medicine, Dumlupinar University, 43100 Kütahya, Turkey. E-mail: drpinarkor@gmail.com

https://doi.org/10.21101/cejph.a5231

\section{INTRODUCTION}

Seasonal influenza is an acute viral upper respiratory tract infection caused by influenza viruses. The most efficient way to prevent influenza is through vaccination. Safe and effective vaccines have been used for more than 60 years (1). The Advisory Committee on Immunization Practices recommends annual vaccination for each individual aged over six months (2). The risk for influenza-related complications, influenza-related hospitalization, and mortality associated with influenza is higher in the elderly and individuals with underlying chronic disease. Influenza vaccination may be less effective in preventing disease, but it reduces the severity of the disease, influenza-related complications, and death in the elderly. Vaccination is especially important for people at higher risk of serious influenza complications $(1,3)$. Therefore, influenza vaccination is recommended by the Centers for Disease Control and Prevention (CDC) and the World Health Organization (WHO) for risk groups $(1,3)$.
Risk groups, as determined by the Scientific Group on Influenza, for influenza vaccination in our country are as follows: individuals aged over 65 years, children aged $<2$ years, pregnant women, residents of long-term care facilities and nursing homes, those with chronic renal failure, asthma, chronic respiratory disease, cardiovascular system disease, diabetes mellitus, neurologic disorders, metabolic disease, chronic liver disease, morbid obesity, immunocompromised people, as well as healthcare workers, and individuals aged 6 months to 18 years who require long-term aspirin use. It is recommended that people in this group should receive a seasonal influenza vaccination (4).

In our country, there are studies indicating influenza vaccination rates for some groups with chronic diseases, but when the studies were scrutinized, it was observed that most of the research was conducted only with individuals in chronic disease groups (5-13). The number of studies in the current literature evaluating influenza vaccination in our country for all chronic diseases is very limited. Also the factors affecting rates of vaccination against 
influenza were not considered in the two studies that evaluated elderly people and adults with chronic diseases together (13, 14). The aim of this study was to evaluate influenza vaccination rates among the elderly and younger individuals with underlying chronic disease, and factors that affect vaccination uptake.

\section{MATERIALS AND METHODS}

We included individuals aged 18-65 years with comorbid diseases such as diabetes mellitus, hypertension, chronic obstructive pulmonary disease (COPD), cardiovascular diseases, chronic renal failure, chronic neurologic disorders, chronic liver disease, malignancy, immunodeficiency, and morbid obesity. We also included individuals aged over 65 years with or without a comorbid disease. We randomly selected the individuals from our outpatient clinics of infectious diseases and internal medicine. Individuals were included in the study after being informed by the principal investigator and obtaining written informed consent from the subjects. Questionnaires were completed by the principal investigator during face-to-face interviews.

The questionnaire was prepared by the researcher by taking examples from previous related studies $(15,16)$. The questionnaire included a total of 23 questions: 8 questions for demographic data; 5 questions for influenza disease and influenza vaccination; and 10 questions on the rate of receiving vaccinations, reasons for not receiving vaccinations, the means of obtaining data about influenza, and which subjects they wanted to have more information on. The study was approved by the local ethics committee. The SPSS version 23 statistics program was used for statistical analysis. Frequencies and percentages are indicated for categorical variables of the participants. The differences between the groups in the study were obtained by interpreting Chi-square analyses. Statistical significance was determined as $\mathrm{p}<0.05$.

\section{RESULTS}

A total of 818 participants were included in the study, 257 (31.4\%) were male. The mean age of participants was $57.47 \pm 14.11$ years; 274 (33.5\%) participants were aged 65 years and over. The demographic data of participants are shown in Table 1. One hundred and three (12.6\%) participants stated that they annually have vaccinations against influenza, 144 (17.6\%) stated that they had vaccination against influenza in the 2015-2016 or 2016-2017 season. Of the participants aged over 65 years, $52(19 \%)$ stated that they had vaccinations for influenza annually, and 75 (27.4\%) stated that they had been vaccinated against influenza in the 2015-2016 or 2016-2017 season. The rate of participants who had never received an influenza vaccine throughout their lives was $68.9 \%(n=564)$. The vaccination rates of participants and their responses to the questions related to influenza are shown in Table 2. The reasons for not getting the influenza vaccine were assessed for the participants who had not received influenza vaccine in the 2015-2016 or 2016-2017 seasons. The most commonly determined reasons for not receiving vaccination were not knowing that the influenza vaccine was necessary (34\%), and believing that they did not need the influenza vaccine because they were healthy $(26 \%)$. The participants' reasons for not receiving influenza vaccines are shown in Table 3.

Table 1. Demographic characteristics of participants $(N=818)$

\begin{tabular}{|l|c|c|}
\hline \multirow{2}{*}{ Characteristic } & \multicolumn{2}{|c|}{ Participants } \\
\cline { 2 - 3 } & $\mathrm{n}$ & $\%$ \\
\hline
\end{tabular}

\begin{tabular}{|l|l|l|}
\hline \multicolumn{3}{|l|}{ Gender } \\
\hline Female & 561 & 68.6 \\
\hline Male & 257 & 31.4 \\
\hline
\end{tabular}

Education

\begin{tabular}{|l|c|c|}
\hline Primary school & 587 & 71.8 \\
\hline Secondary school & 60 & 7.3 \\
\hline High school & 65 & 7.9 \\
\hline University & 47 & 5.7 \\
\hline No education & 59 & 7.2 \\
\hline
\end{tabular}

Occupation

\begin{tabular}{|l|c|c|}
\hline Housewife & 527 & 64.4 \\
\hline Retired & 118 & 14.4 \\
\hline Worker & 62 & 7.6 \\
\hline Officer & 26 & 3.2 \\
\hline Self-employment & 82 & 10 \\
\hline Student & 3 & 0.4 \\
\hline
\end{tabular}

Marital Status

\begin{tabular}{|l|c|c|}
\hline Married & 674 & 82.4 \\
\hline Single & 37 & 4.5 \\
\hline Widow & 107 & 13.1 \\
\hline
\end{tabular}

Income

\begin{tabular}{|l|c|c|}
\hline Low & 239 & 29.2 \\
\hline Medium & 505 & 61.7 \\
\hline Good & 74 & 9 \\
\hline
\end{tabular}

Region

\begin{tabular}{|l|l|l|}
\hline City centre & 649 & 79.3 \\
\hline Rural & 169 & 20.7 \\
\hline
\end{tabular}

Underlying Chronic Disease

\begin{tabular}{|l|c|c|}
\hline No & 17 & 2.1 \\
\hline Yes & 801 & 97.9 \\
\hline Diabetes mellitus & 438 & 53.5 \\
\hline Hypertension & 368 & 45.0 \\
\hline $\begin{array}{l}\text { Chronic obstructive pulmonary } \\
\text { disease }\end{array}$ & 124 & 15.2 \\
\hline Chronic cardiovascular disease & 165 & 20.2 \\
\hline Chronic renal failure & 48 & 5.9 \\
\hline Chronic neurological disease & 13 & 1.6 \\
\hline Chronic liver disease & 75 & 9.2 \\
\hline Malignancy & 19 & 2.3 \\
\hline Immunodeficiency & 5 & 0.6 \\
\hline Morbid obesity & 37 & 4.5 \\
\hline Rheumatological disease & 33 & 4.0 \\
\hline Chronic metabolic disease & 71 & 8.7 \\
\hline Other & 29 & 3.5 \\
\hline
\end{tabular}


Table 2. Vaccination rate of participants and their answers for information questions about influenza $(N=818)$

\begin{tabular}{|c|c|c|c|}
\hline & \multicolumn{3}{|c|}{ Participants } \\
\hline & & $\mathrm{n}$ & $\%$ \\
\hline \multirow{3}{*}{ İnfluenza is an airborne disease passed via respiratory droplets. } & Yes & 438 & 53.5 \\
\hline & No & 118 & 14.4 \\
\hline & I do not know & 262 & 32.1 \\
\hline \multirow{3}{*}{ Handwashing regularly protects against influenza. } & Yes & 644 & 78.7 \\
\hline & No & 82 & 10.0 \\
\hline & I do not know & 92 & 11.2 \\
\hline \multirow{3}{*}{$\begin{array}{l}\text { Influenza vaccine should be administered to individuals with chronic } \\
\text { diseases and elderly people. }\end{array}$} & Yes & 389 & 47.6 \\
\hline & No & 140 & 17.1 \\
\hline & I do not know & 289 & 35.3 \\
\hline \multirow{3}{*}{ Influenza vaccine protects against the influenza viruses. } & Yes & 432 & 52.8 \\
\hline & No & 153 & 18.7 \\
\hline & I do not know & 233 & 28.5 \\
\hline \multirow{3}{*}{ Influenza vaccine causes influenza illness. } & No & 307 & 37.5 \\
\hline & Yes & 160 & 19.6 \\
\hline & I do not know & 351 & 42.9 \\
\hline \multirow{3}{*}{ The influenza vaccine should be repeated every year. } & Yes & 372 & 45.5 \\
\hline & No & 160 & 19.6 \\
\hline & I do not know & 286 & 35.0 \\
\hline \multirow{3}{*}{ Influenza vaccine is necessary. } & Yes & 353 & 43.2 \\
\hline & No & 230 & 28.1 \\
\hline & I do not know & 235 & 28.7 \\
\hline \multirow{2}{*}{ Received influenza vaccine regularly } & Yes & 103 & 12.6 \\
\hline & No & 715 & 87.4 \\
\hline \multirow{2}{*}{ Received influenza vaccine throughout their life } & Yes & 237 & 29.0 \\
\hline & No & 564 & 68.9 \\
\hline \multirow{2}{*}{ Received influenza vaccine in $2015-2016$ or 2016-2017 season } & Yes & 144 & 17.6 \\
\hline & No & 674 & 82.4 \\
\hline
\end{tabular}

Table 3. Reasons of participants for not getting influenza vaccine $(N=674)$

\begin{tabular}{|l|c|c|}
\hline \multirow{2}{*}{} & $\mathbf{2}$ & Participants \\
\cline { 2 - 3 } & $\mathbf{n}$ & 122 \\
\hline My physician did not state that I had to get vaccinated. & 229 & 18.1 \\
\hline I did not know that I have to get influenza vaccination. & 87 & 34.0 \\
\hline I am afraid of side effects that can develop after vaccination. & 107 & 12.9 \\
\hline I do not think the vaccine gives overall protection against influenza. & 69 & 15.9 \\
\hline I do not think the vaccine is safe. & 23 & 10.2 \\
\hline In general, I am against vaccination. & 174 & 3.4 \\
\hline I do not need to get vaccinated because I am healthy. & 34 & 25.8 \\
\hline Influenza is not a dangerous disease. & 37 & 5.0 \\
\hline I do not have time for vaccination. & 7 & 5.5 \\
\hline Vaccination is expensive. I do not have enough money. & 10 & 1.0 \\
\hline Other & & 1.6 \\
\hline
\end{tabular}

Participants could select more than one reason. 
Table 4. Sources where participants wanted to have information about influenza $(N=818)$

\begin{tabular}{|l|c|c|}
\hline \multirow{2}{*}{} & \multicolumn{2}{|c|}{ Participants } \\
\cline { 2 - 3 } & $\mathbf{n}$ & $\%$ \\
\hline Family physician & 538 & 65.8 \\
\hline Physician following me for my chronic disease & 461 & 56.4 \\
\hline Health authority (Ministry of Health) & 100 & 12.2 \\
\hline Television & 70 & 8.6 \\
\hline Internet & 18 & 2.2 \\
\hline Newspaper & 8 & 1.0 \\
\hline Other (pharmacy) & 1 & 0.1 \\
\hline
\end{tabular}

Participants could select more than one source.

When the sources of information about influenza of all participants were assessed, the sources were stated as follows: 359 (43.9\%) from physician, 56 (6.8\%) from nurse, 437 (53.4\%) from television, $45(5.5 \%)$ from newspaper, 35 (4.3\%) from the internet, and 35 (4.3\%) from others (family, neighborhood, pharmacy, experience), with $15(1.2 \%)$ having no knowledge. One hundred and eighty-six (22.7\%) participants believed that they had sufficient information about influenza, 411 (50.2\%) believed that they had insufficient information, and 221 (27\%) stated that they were not sure.

The participants stated that they wanted to have more information about the following subjects: health problems that can be caused by influenza (46.9\%), success rates of influenza vaccines in preventing disease $(47.7 \%)$, vaccine-associated adverse effects $(33.5 \%)$, individuals at risk who are recommended to receive the influenza vaccines $(24 \%)$, other reasons (e.g. how the vaccine is obtained, the contagiousness of the disease, time for vaccination) $(0.6 \%)$. The sources that participants preferred to use to learn information about influenza are shown in Table 4.

The rates of living in the city centre, being over 65 years old and educated participants who were vaccinated were statistically significantly higher $(\mathrm{p}<0.05)$ compared with non-vaccinated and vaccinated uneducated people. It was determined that people with COPD and cardiovascular disease were vaccinated statistically significantly less when we compared vaccinated and unvaccinated people $(\mathrm{p}<0.05)$. No statistically significant difference was observed for the other parameters $(\mathrm{p}>0.05)$.

The rate of replying to information questions about influenza and the rate of considering the influenza vaccine to be necessary were statistically significantly higher in the participants who received the influenza vaccine $(\mathrm{p}<0.05)$. Among the participants who had experience with the influenza vaccine, the rate of receiving the influenza vaccine was statistically significantly higher than in the participants who had never received the influenza vaccine in their lives $(p<0.05)$. Statistically significantly more participants were vaccinated who acquired information from a physician than participants who gained information from the other sources $(p<0.05)$. It was determined that participants who believed they had sufficient information about influenza were vaccinated statistically significantly more than patients who had less conviction about their knowledge $(\mathrm{p}<0.05)$ (Table 5).
Table 5. Comparison of data of vaccinated and non-vaccinated participants $(N=818)$

\begin{tabular}{|c|c|c|c|}
\hline & $\begin{array}{c}\text { Vaccinated } \\
(n=144)\end{array}$ & $\begin{array}{c}\text { Non-vaccinated } \\
(n=674)\end{array}$ & p-value \\
$\%$ & $\%$ & \\
\hline
\end{tabular}

\begin{tabular}{|c|c|c|c|}
\hline \multicolumn{4}{|l|}{ Gender } \\
\hline Female & 68.1 & 68.7 & \multirow{2}{*}{0.881} \\
\hline Male & 31.9 & 31.3 & \\
\hline \multicolumn{4}{|l|}{ Education } \\
\hline Primary school & 66.0 & 73.0 & \multirow{5}{*}{0.027} \\
\hline Secondary school & 5.6 & 7.7 & \\
\hline High school & 9.7 & 7.6 & \\
\hline University & 5.6 & 5.8 & \\
\hline Lack of education & 13.2 & 5.9 & \\
\hline
\end{tabular}

\begin{tabular}{|l|c|c|c|}
\hline Occupation & \multicolumn{1}{|l|}{} \\
\cline { 1 - 3 } Housewife & 63.9 & 64.5 & \\
\hline Retired & 17.4 & 13.8 & \multirow{2}{*}{0.423} \\
\hline Worker & 4.2 & 8.3 & \\
\hline Officer & 4.2 & 3.0 & \\
\cline { 1 - 3 } Self-employment & 10.4 & 9.9 & \\
\hline Student & 0.0 & 0.4 & \\
\hline & & &
\end{tabular}

\begin{tabular}{|l|c|c|c|}
\hline Marital status \\
\cline { 1 - 3 } Married & 77.8 & 83.4 & \multirow{2}{*}{0.} \\
\cline { 1 - 3 } Single & 4.2 & 4.6 & \\
\hline Widow & 18.1 & 12.0 & \\
\hline
\end{tabular}

\begin{tabular}{|l|c|c|}
\hline \multicolumn{3}{|l|}{ Income } \\
\hline Low & 25.0 & 30.1 \\
\hline Medium & 64.6 & 61.1 \\
\hline Good & 10.4 & 8.8 \\
\hline
\end{tabular}

Place of residence

\begin{tabular}{|l|l|l|l|}
\hline City centre & 86.1 & 77.9 & \multirow{2}{*}{0.027} \\
\cline { 1 - 3 } Rural & 13.9 & 22.1 & \\
\hline
\end{tabular}

Age

\begin{tabular}{|l|c|c|c|}
\hline Younger than 65 years & 47.9 & 70.5 & \multirow{2}{*}{$<0.001$} \\
\hline Older than 65 years & 52.1 & 29.5 & \\
\hline Underlying chronic disease & 96.5 & 98.2 & 0.196 \\
\hline Diabetes mellitus & 56.9 & 52.8 & 0.368 \\
\hline $\begin{array}{l}\text { Chronic obstructive } \\
\text { pulmonary disease }\end{array}$ & 27.8 & 12.5 & $<0.001$ \\
\hline Chronic cardiovascular disease & 26.4 & 18.8 & 0.041 \\
\hline Immunodeficiency & 2.8 & 0.1 & - \\
\hline Chronic renal failure & 4.2 & 6.2 & 0.339 \\
\hline Chronic liver disease & 4.9 & 10.1 & 0.048 \\
\hline Malignancy & 4.2 & 1.9 & 0.106 \\
\hline Rheumatological disease & 2.1 & 4.5 & 0.190 \\
\hline Chronic metabolic disease & 6.3 & 9.2 & 0.254 \\
\hline Morbid obesity & 4.9 & 4.5 & 0.830 \\
\hline Chronic neurological disease & 2.1 & 1.5 & 0.601 \\
\hline Hypertension & 53.5 & 43.2 & 0.024 \\
\hline \multicolumn{2}{|c|}{ Continued on the next page }
\end{tabular}


Continued from the previous page

Table 5. Comparison of data of vaccinated and non-vaccinated participants $(N=818)$

\begin{tabular}{|c|c|c|c|}
\hline & $\begin{array}{c}\text { Vaccinated } \\
(n=144) \\
\%\end{array}$ & $\begin{array}{c}\text { Non-vaccinated } \\
(n=674) \\
\%\end{array}$ & $p$-value \\
\hline $\begin{array}{l}\text { Influenza is an airborne dis- } \\
\text { ease passed via respiratory } \\
\text { droplets. }\end{array}$ & 62.5 & 51.6 & 0.015 \\
\hline $\begin{array}{l}\text { Influenza vaccine should be } \\
\text { administered to individuals } \\
\text { with chronic diseases and } \\
\text { elderly people. }\end{array}$ & 87.5 & 76.9 & 0.015 \\
\hline $\begin{array}{l}\text { The influenza vaccine does } \\
\text { not cause influenza illness. }\end{array}$ & 81.3 & 46.7 & $<0.001$ \\
\hline $\begin{array}{l}\text { The influenza vaccine should } \\
\text { be repeated every year. }\end{array}$ & 60.4 & 32.6 & $<0.001$ \\
\hline $\begin{array}{l}\text { Is the influenza vaccine } \\
\text { necessary? Yes/No }\end{array}$ & 73.6 & 39.5 & $<0.001$ \\
\hline $\begin{array}{l}\text { The seasonal influenza vac- } \\
\text { cine protects us against the } \\
\text { influenza viruses. }\end{array}$ & 79.2 & 40.8 & $<0.001$ \\
\hline $\begin{array}{l}\text { Have you ever received an } \\
\text { influenza vaccine throughout } \\
\text { your life? Yes/No }\end{array}$ & 63.8 & 1.8 & $<0.001$ \\
\hline \multicolumn{4}{|l|}{ Source of knowledge acquisition } \\
\hline Physician & 64.6 & 39.5 & $<0.001$ \\
\hline Nurse & 6.9 & 6.8 & 0.959 \\
\hline TV & 31.3 & 58.2 & 0.259 \\
\hline Newspaper & 3.5 & 5.9 & 0.404 \\
\hline Internet & 5.6 & 4.0 & 0.218 \\
\hline \multicolumn{4}{|c|}{ Do you think that you have sufficient information about influenza? } \\
\hline Yes & 43.1 & 18.4 & \multirow{3}{*}{$<0.001$} \\
\hline No & 28.5 & 54.9 & \\
\hline Not sure & 28.5 & 26.7 & \\
\hline
\end{tabular}

\section{DISCUSSION}

The WHO and the European Union(EU) state that the minimum influenza vaccination target for adults is $75 \%$. However, troubles in achieving the targeted vaccination rates are reported by health authorities (17-19). It was disclosed that the $75 \%$ target vaccination rate against influenza was reached in only two member states of the EU (the United Kingdom and the Netherlands) (19). In a study performed in Germany related to influenza vaccination in the adult population, vaccination rates were determined as follows: $24 \%$ in individuals aged $\leq 60$ years with underlying disease, $56 \%$ in individuals aged $\geq 60$ years with underlying disease, and $53 \%$ in individuals aged over 65 years (15).

When Turkish data were assessed, it was determined that the results of certain disease groups were reported in most of the studies investigating influenza vaccination rates. In the first study by Biberoglu et al. (13) that evaluated all relevant risk groups and the elderly together, the influenza vaccination rates in indi- viduals aged over 65 years, individuals with COPD, and those with diabetes mellitus were reported as $5.9 \%, 14.9 \%$, and $9.1 \%$, respectively. In another study performed by Oncel et al. (14), the authors determined influenza vaccination rates in individuals aged over 65 years and individuals with chronic diseases as $6.7-27.3 \%$. In our study, influenza vaccination rates in the adult population, individuals aged over 65 years, and individuals with diabetes mellitus, COPD, chronic cardiovascular disease, and chronic renal failure were determined as $12.5-32.2 \%$. The results obtained in our study and similar studies show that influenza vaccination rates in risk groups among the elderly and adults are insufficient. Therefore, we think that setting goals for influenza vaccination rates in adults and follow-up vaccination rates in target groups will contribute to increasing vaccination rates.

In a study performed by Bödeker et al. (15) in Germany, the authors evaluated the reasons of participants for not receiving vaccinations against influenza, and they reported these reasons as disbelief in vaccines and believing themselves to be in the low-risk group for influenza. In a study performed in Jordan, adverse effects and insufficient efficacy of the influenza vaccine were reported as reasons for not receiving a vaccination (20). The most frequent reasons for the participants to not receive the influenza vaccine in our study were as follows: not knowing it was necessary to get an influenza vaccine, specifying that it was not necessary to have an influenza vaccine because they were healthy, and not being recommended the vaccine by a physician. Thus, in our study, the reasons for not receiving a vaccination were similar to those reported in the world literature $(15,18,20,21)$. We think that increasing the knowledge level and awareness of the adult population about the risk groups and the efficiency and adverse effects of the vaccine will contribute to increasing vaccination rates.

One of the important results obtained in our study was that the lack of physician recommendation was among the leading reasons for not getting a vaccination. Additionally, the participants in our study were asked about where they wanted to receive information about influenza, and the participants responded that they wanted to be informed first by their family physicians, and second by the physicians who treated them for their chronic diseases. This shows that recommendations for the vaccine by physicians for individuals in risk groups and the elderly could be considered among the most important steps needed to increase the awareness of vaccinations and vaccination rates.

In one study performed to evaluate the factors affecting influenza vaccination, those aged over 60 years, those who graduated from a university, those with health insurance, and those with a health risk were vaccinated significantly more than non-vaccinated individuals (14). In another study, older age, working situation, presence of underlying disease, medical visit within the past year, presence of vaccine recommendation by a healthcare professional, a past history of influenza vaccination, being informed about the influenza vaccine and the influenza disease, and a positive attitude were determined as being significant for acceptance of the influenza vaccine, which is aligned with our results (22).

\section{CONCLUSION}

In conclusion, in our study, the knowledge level about influenza, vaccination rates, and factors that affected vaccination 
uptake in the elderly and adults with underlying disease were evaluated. Our study provides important information about the need for increasing awareness of influenza and the vaccination of participants. Therefore, physicians informing target risk groups about influenza vaccination and increasing general awareness of influenza may contribute to improving our vaccination rates.

\section{Conflict of Interests}

None declared

\section{REFERENCES}

1. World Health Organization. Influenza (Seasonal) [Internet]. Geneva: WHO; 2018 [cited 2018 Nov 7]. Available from: http://www.who.int news-room/fact-sheets/detail/influenza-(seasonal).

2. Grohskopf LA, Sokolow LZ, Broder KR, Olsen SJ, Karron RA, Jernigan $\mathrm{DB}$, et al. Prevention and control of seasonal influenza with vaccines. MMWR Recomm Rep. 2016;65(5):1-54.

3. Centers for Control and Disease Prevention. Recommended immunization schedule for adults aged 19 years or older, United States, 2018 [Internet] CDC; 2018 [cited 2018 Nov 7]. Available from: https://www.cdc.gov/ vaccines/schedules/downloads/adult/adult-combined-schedule.pdf.

4. Turkish Republic Health Government. Seasonal influenza [Internet]. 2017 [cited 2018 Nov 7]. Available from: https://www.grip.gov.tr/tr/grip-asisi. html. (In Turkish.)

5. Bülbül Y, Öztuna F, Gülsoy A, Özlü T. Chronic obstructive pulmonary disease in Eastern Black Sea Region: characteristics of the disease and the frequency of influenza-pneumococcal vaccination. Turkiye Klinikleri J Med Sci. 2010;30:24-9.

6. Balbay EG, Tanrıverdi E, Alaşan F, Özmen Süner K. The frequency of vaccination in patients with chronic obstructive pulmonary disease in Düzce. J Duzce Univ Health Sci Inst. 2013;3(2):15-7. (In Turkish.)

7. Balcıoğlu H, Ulus T, Sarı YE, Bilge U, Ünlüoğlu İ. Flu vaccination rates in the patients with coronary artery disease and motivation. Osmangazi J Med. 2017;39(1):26-30. (In Turkish.)

8. Kaya A, Altınel N, Karakaya G, Çetinkaya F. Knowledge and attitudes among patients with asthma and parents and physicians towards influenza vaccination. Allergol Immunopathol (Madr). 2017 May-Jun;45(3):240-3.

9. Arslan IE, Altınova A, Baloș Törüner F, Yalçın MM, Özkan C, Çakır $\mathrm{N}$, et al. Awareness of hepatitis $\mathrm{B}$, influenza and pneumococcal vaccine among diabetic patients. GMJ 2016;27:115-7. (In Turkish.)

10. Urun Y, Akbulut H, Demirkazik A, Cay Senler F, Utkan G, Onur H, et al. Perception about influenza and pneumococcal vaccines and vaccination coverage among patients with malignancies and their family members. J BUON. 2013;18(3):511-5.

11. Ciblak MA; Grip Platformu. Influenza vaccination in Turkey: prevalence of risk groups, current vaccination status, factors influencing vaccine uptake and steps taken to increase vaccination rate. Vaccine. 2013;31(3):518-23.

12. Aka Aktürk Ü, Görek Dilektaşlı A, Şengül A, Musaffa Salepçi B, Oktay $\mathrm{N}$, Düger $\mathrm{M}$, et al. Influenza and pneumonia vaccination rates and factors affecting vaccination among patients with chronic obstructive pulmonary disease. Balkan Med J. 2017;34(3):206-11.

13. Biberoglu K. Come on adults, lets get vaccinated. Actual Med. 2006;14:18-26. (In Turkish.)

14. Oncel S, Turhan O, Huseyin PH, Yalcin AN. Status of influenza vaccination in patients presenting to two neighborhood primary healthcare clinics in Antalya. Infez Med. 2008;16(2):74-9.

15. Bödeker B, Remschmidt C, Schmich P, Wichmann O. Why are older adults and individuals with underlying chronic diseases in Germany not vaccinated against flu? A population-based study. BMC Public Health. 2015 Jul 7;15:618. doi: 10.1186/s12889-015-1970-4.

16. Evans MR, Watson PA. Why do older people not get immunised against influenza? A community survey. Vaccine. 2003;21(19-20):2421-7.

17. World Health Oganization. Prevention and control of influenza pandemics and annual epidemics [Internet]. Geneva: WHO; 2003 [cited 2018 Nov 7]. Available from: https://apps.who.int/iris/handle/10665/78320.

18. Bof de Andrade F, Sayuri Sato AP, Moura RF, Ferreira Antunes JL. Correlates of influenza vaccine uptake among community-dwelling older adults in Brazil. Hum Vaccin Immunother. 2017;13(1):103-10.

19. European Centre for Disease Prevention and Control. Risk assessment: Seasonal influenza 2012/13 in Europe (EU/EEA countries) [Internet]. ECDC; 2013 [cited 2018 Nov 7]. Available from: https://ecdc.europa.eu/ en/publications-data/risk-assessment-seasonal-influenza-201213-europeeueea-countries.

20. Assaf AM, Hammad EA, Haddadin RN. Influenza vaccination coverage rates, knowledge, attitudes, and beliefs in Jordan: a comprehensive study. Viral Immunol. 2016;29(9):516-25.

21. Tsai YY, Lee JJ, Hsieh WH. Determinants of the public intent to receive the seasonal influenza vaccine and protective behaviors: a populationbased study in Taiwan. Vaccine. 2014;32(49):6667-75.

22. Worasathit R, Wattana W, Okanurak K, Songthap A, Dhitavat J, Pitisuttithum P. Health education and factors influencing acceptance of and willingness to pay for influenza vaccination among older adults. BMC Geriatr 2015;15:136. doi: 10.1186/s12877-015-0137-6.

Received October 13, 2017 Accepted in revised form February 7, 2019 